\title{
LIVRO DIDÁTICO DE GEOGRAFIA E DE HISTÓRIA NA REALIDADE PAULISTANA: UMA REFLEX ̃̃O SOBRE O PNLD E A POLÍTICA DE DISTRIBUIÇÃO DE CADERNOS DE ENSINO PELO GOVERNO DO ESTADO DE SÃO PAULO
}

\author{
Júlio César Suzuki ${ }^{1}$ \\ João Gabriel Nogueira Romano ${ }^{2}$ \\ Denise Martins de Sousa ${ }^{3}$
}

\begin{abstract}
Resumo
O uso do livro didático, no ensino formal, precisa ser compreendido em sua intrínseca relação com a historicidade e contextualidade da educação escolar no país, sendo que inúmeros pesquisadores condenam o seu uso, enquanto outros o defendem, mesmo reconhecendo seus limites e dificuldades. Assim, no contexto do significado do livro didático, inserido como política estatal de sua distribuição, objetivamos, neste trabalho, analisar a política nacional e estadual de livro didático, voltada para o segundo ciclo do ensino fundamental, tendo como foco o processo de sua escolha, o que impõe a valorização dos seus sujeitos sociais essenciais (professores e coordenadores pedagógicos/direção), em duas escolas públicas estaduais do município de São Paulo: Escola Estadual Prof. Cândido Gonçalves Gomide e Escola Estadual Eusébio de Paula Marcondes.
\end{abstract}

Palavras-chave: Livro Didático. PNLD. Ensino Médio. Educação Básica.

\begin{abstract}
The use of didactic book, in formal teaching, needs to be comprehended in its intrinsic relationship to historicity and contextuality of school education in the country. Many researchers condemn its usage, while others defend it, even recognizing its limitations and difficulties. Therefore, within the context of the didactic textbook significance, inserted as a state policy of its distribution, we intend, in this study, to analyze the national and state policy of didactic textbook, regarding the second cycle of basic education focusing on the process of their choice, which requires the valuation of its essential social subjects (teachers and pedagogic coordinators/principals), in two state public schools of the São Paulo city: State School Prof. Cândido Gonçalves Gomide and State School Eusébio de Paula Marcondes.
\end{abstract}

Keywords: Didactic Book. PNLD. Junior High School. Basic Education.

\section{INTRODUÇÃO}

O livro didático só pode ser entendido no interior da sua historicidade e da contextualidade específica da educação escolar no país, como material de apoio fundamental à prática pedagógica:

\footnotetext{
${ }^{1}$ Autor, Professor Doutor (Departamento de Geografia/FFLCH/USP), Graduado em Geografia (UFMT) e em Letras (UFPR), com Mestrado e Doutorado em Geografia Humana (USP) e pós-doutorado pela Université Panthéon-Sorbonne. Endereço eletrônico: jcsuzuki@ usp.br.

2 Co-autor, Graduado em Ciências Sociais da Universidade de São Paulo. Mestrando em Sociologia/FFLCH/USP. Endereço eletrônico: jgnr@usp.br.

3 Co-autora, Graduada em Geografia da Universidade de São Paulo. Endereço eletrônico: denisegeo@gmail.com.
} 
"É apenas no interior da historicidade e da contextualidade específica de uma dada situação que poderemos avaliar com clareza o significado das diversas alternativas da geografia escolar e do seu material de apoio" (VESENTINI, 1989:166).

Muitos pesquisadores, por um lado, condenam seu uso, afirmando que os professores os utilizam sem critério algum, apenas como instrumento de um trabalho sem grande reflexão ou como liame fundamental do discurso da competência:

“(...) o que se constata na realidade é que o livro didático constitui um elo importante na corrente do discurso da competência: é o lugar do saber definido, pronto, acabado, correto e, dessa forma, fonte última de referência e contrapartida dos erros das experiências de vida. Ele acaba assim tomando a forma de critério do saber (...)" (VESENTINI, 1989:166).

Por outro, alguns professores defendem a sua utilização com ressalvas. No entanto, ainda, é grande a dificuldade que enfrentam aqueles docentes que não o querem adotar como instrumento do processo ensino-aprendizagem.

Os defensores do uso do livro didático, em sala de aula, também, reconhecem os problemas que o seu uso pode gerar por se constituir em um corpo estranho, com objetivos fixados fora dos propósitos estabelecidos pelos professores que se valem deste instrumento de ensino. (BLOIS, 1979:7)

Mesmo que muitos sejam contra os livros didáticos, com argumentos coerentes, os livros didáticos são uma realidade, cada vez mais, abrangente em nosso país, envolvendo, anualmente, uma quantia volumosa de exemplares a ser distribuída principalmente pelo Governo Federal. (CASSIANO, 2005)

Assim, no contexto do significado do livro didático, inserido como política estatal de sua distribuição, objetivamos, neste trabalho, analisar a política nacional e do Governo do Estado de São Paulo de livro didático, voltada para o segundo ciclo do ensino fundamental, tendo como foco o processo de sua escolha, nas disciplinas de Geografia e História, o que impõe a valorização dos seus sujeitos sociais essenciais (professores e coordenadores pedagógicos/direção), em duas escolas públicas estaduais do município de São Paulo: Escola Estadual Prof. Cândido Gonçalves Gomide e Escola Estadual Eusébio de Paula Marcondes. 


\title{
2 OS LIVROS DIDÁTICOS DE GEOGRAFIA E DE HISTÓRIA NO BRASIL E A POLÍTICA NACIONAL DE LIVRO DIDÁTICO
}

No Brasil, os primeiros livros didáticos foram impressos pela Imprensa Régia, em 1867, trazendo conhecimentos reproduzidos ao longo de um ensino que privilegiava a transmissão de informações. (SOARES, 1993:61)

A princípio, foram utilizados livros franceses. Somente, no início do século XX, autores brasileiros, em grande medida, fundados em traduções feitas dos originais franceses, começam a publicar seus livros no Brasil, ainda, bastante marcados pela transmissão de informações. (PETRONE, 1993:13)

Delgado de Carvalho foi um dos mais importantes autores de livros didáticos de Geografia do início do século XX, fugindo de um padrão centrado na memorização e na divisão administrativa, já que se preocupava com a relação entre o homem e o meio, entendendo a terra como habitat do homem.

\begin{abstract}
“(...) D. de Carvalho, em sua luta pela edificação da geografia moderna, ou melhor, científica, insurgiu-se sempre contra a geografianomenclatura, de que resultara o privilegiamento, principalmente na escola, da memorização; ao mesmo tempo, empenhou-se contra a geografia administrativa, isto é, o estudo da geografia do Brasil a partir de sua divisão em Estados-membros. Pois, a seu ver, a geografia-nomenclatura elou administrativa havia impedido até então a fundamentação lógica imprescindível à geografia científica que desejava aqui implantar definitivamente" (VLACH, 1989:151)
\end{abstract}

Suas mais importantes obras foram Geografia do Brasil, em 1920, e Geografia Regional do Brasil na década de 1940. No entanto, Delgado de Carvalho atuou para além da atividade de escritor de livro didático, tendo exercido o magistério, além da realização de pesquisas científicas, bem como tendo sido um dos responsáveis pela criação da disciplina de Geografia no Colégio Pedro II. (PETRONE, 1993:13)

Outros autores que se destacaram na Geografia escolar foram Alfredo Allis Júnior e Aroldo de Azevedo. (PETRONE, 1993:13)

A partir da década de 1930, o ensino tornou-se mais democrático, em nosso país, o que possibilitou o acesso à educação de camadas menos favorecidas economicamente, 
permitindo, como conseqüência, o desenvolvimento do mercado consumidor do livro didático, no qual se pregava, em termos gerais, o bom comportamento, além de se transmitirem visões idealizadas das desigualdades sociais, reforçando conteúdos curriculares. (FREITAG; COSTA; MOTTA, 1989)

Com a Era Vargas, os problemas relativos ao significado ideológico do livro didático se acentuam, tendo em vista o seu poder na transmissão de certa visão de mundo, necessária ao controle da sociedade pelo Estado. Assim, a presença do Estado não se ausenta, desde então, no que concerne à produção e à circulação do livro didático. (SCHÄFFER, 1998:131)

O Instituto Nacional do Livro (INL), criado, em 1937, como órgão subordinado ao Ministério da Educação, propunha-se a estimular as políticas editoriais e serviços bibliotecários, sendo que, em 1938, foi criada a Comissão Nacional do Livro Didático (CNLD), incumbida de examinar e julgar os livros didáticos, de indicar livros importantes para tradução e de promover concursos pra a produção de determinados livros didáticos não existentes no país (SCHÄFFER, 1998:131), tanto que Bárbara Freitag, Wanderly F. da Costa e Valéria R. Motta (1989:28) afirmam que essa comissão tinha muito mais a função de um controle político-ideológico que propriamente didática, já que as obras que não tivessem autorização prévia, concedida pelo Ministério da Educação, não podiam ser adotadas em escolas.

A produção do livro tornou-se uma necessidade, tendo em vista o significativo aumento do número de crianças que passaram a freqüentar escolas, estimuladas por um governo que procurava inserir o país no processo de industrialização, necessitando, para tal, de mão de obra qualificada para os padrões técnicos da época.

Estes novos alunos contribuíram para que houvesse o crescimento da produção editorial. No entanto, para que o livro didático circulasse em sala de aula, era necessário que houvesse sua adequação aos cursos, aos programas curriculares e aos modelos que se procuravam transmitir, na escola, pelo Estado.

A partir dos anos 1960, a produção do livro aumenta consideravelmente, principalmente por conta da modernização da indústria gráfica, além do governo passar a investir, de forma planejada, na cultura, reformulando, patrocinando e criando instituições que congregavam escritores. Assim, fortaleceram-se outros órgãos, como o Conselho Federal de Cultura e o Instituto Nacional do Livro. Em 1968, criou-se a 
Fundação Nacional do Livro Infantil e Juvenil, com o objetivo de promover o livro e a leitura infanto-juvenis, o que contribui para o crescimento da indústria do livro didático e do seu mercado consumidor. (MUNAKATA, 1997:38)

A Fundação Nacional de Material Escolar (FENAME), criada em outubro de 1967, absorveu os programas desenvolvidos pela extinta Campanha Nacional do Material de Ensino. A FENAME tinha como finalidade básica a produção e a distribuição de material didático às instituições escolares, mas, efetivamente, não contava com organização administrativa nem recursos financeiros para desempenhar tal tarefa. Em decorrência dessa situação de fragilidade no alcance do seu objetivo fundamental, em 1970, foi implantado o sistema de co-edição com as editoras nacionais, por intermédio da Portaria Ministerial n.35/70. (HOFLING, 2000:163)

Em 1971, é extinta a Comissão do Livro Técnico e Didático (COLTED) e, em seu lugar, é criado o Programa do Livro Didático (PLID), conforme o Decreto Federal n. 68.728 , de 08 de junho de 1971.

Em 1976, a FENAME sofreu modificações por Decreto presidencial, passando a ser encarregada de assumir o Programa do Livro Didático, até então sob a responsabilidade do Instituto Nacional do Livro (INL), por sua vez, subordinado ao MEC. Com o sistema de co-edição, de censor oficial dos livros didáticos usados nas escolas brasileiras, o Estado, também, foi assumindo o papel de financiador desses livros. (FREITAG; COSTA; MOTTA, 1989:15)

Em abril de 1983, foi criada a Fundação de Assistência ao Estudante (FAE), absorvendo os programas que eram da alçada da FENAME e do Instituto Nacional de Assistência ao Educando (INAE), órgãos vinculados ao MEC. No mesmo ano, o Programa do Livro Didático (PLID) foi incorporado à FAE. Em 1984, deu-se fim ao sistema de co-edição, passando o MEC a ser comprador dos livros produzidos pelas editoras participantes do PLID. (HOFLING, 2000:164)

Posteriormente, em 1985, o Programa do Livro Didático é transformado em PNLD (Programa Nacional do Livro Didático) que, até hoje, distribui livros para as crianças que frequentam escolas públicas, sem distinções entre alunos carentes ou nãocarentes. Este programa tinha, inicialmente, por objetivo distribuir livros didáticos a todos os alunos do Ensino Fundamental das escolas da rede pública de ensino. 
Desde seu início, o programa previa a participação dos professores no processo de escolha dos livros e a sua aquisição junto às editoras. Para que isso se viabilizasse, a FAE relacionava, sem qualquer critério avaliativo, praticamente toda a produção didática do país. A exigência era que o atendimento fosse feito com livros nãodescartáveis, com durabilidade de três anos, para serem reutilizados por outros estudantes pelo menos nos dois anos seguintes ao da distribuição. Assim, os livros não eram doados, mas emprestados aos alunos para o trabalho escolar, sendo, então, devolvidos no final do ano letivo. (OLIVEIRA, 1983:91)

A FAE promovia a escolha dos livros didáticos junto às escolas, enviando, por meio das Secretarias Estaduais de Educação, os manuais com a relação de títulos oferecidos e os formulários para indicação dos livros pelos professores. Desta forma, cada Secretaria de Educação coordenava o PNLD em seu Estado, muito embora a compra para todo o Brasil fosse feita pela FAE. Assim, a partir da criação do PNLD, em 1985, o Estado, sofrendo todo o tipo de pressão por parte dos lobbies das editoras, passou a ser o maior comprador de livros didáticos do país. (CARVALHO, 1991:33)

Há mais de uma década, em 1996, o PNLD sofreu alterações, principalmente quanto à compra de livros que começou a passar por análises de qualidade do material, em que se pese a pressão da sociedade, dos intelectuais e, principalmente, da mídia, com denúncias constantes em relação às obras de péssima qualidade distribuídas pelo programa.

O Programa Nacional de Livro Didático, atualmente, possui como objetivo oferecer a alunos e professores de escolas públicas do ensino fundamental, de forma universal e gratuita, livros didáticos e dicionários de Língua Portuguesa de qualidade para apoio ao processo ensino-aprendizagem desenvolvido em sala de aula.

A avaliação sistemática das obras, inscritas no PNLD, é coordenada, desde 1996, pela Secretaria de Educação Básica, vinculada ao MEC, em parceria com universidades públicas brasileiras, responsáveis pela avaliação de livros das seguintes áreas: Geografia, História, Língua Portuguesa, Matemática, Ciências, Alfabetização e Dicionário da Língua Portuguesa.

Ao final de cada processo de avaliação das obras inscritas, é confeccionado um guia, com a resenha daquelas indicadas pelo grupo de pareceristas (professores da rede 
pública e de universidades, sobretudo, federais e estaduais), bem como com os critérios, os princípios e as fichas de avaliação.

Em relação aos livros didáticos de Geografia e de História, somente, em 1997, começou a sua distribuição pelo PNLD.

\section{PNLD, ESCOLAS E PROFESSORES}

Durante os meses de outubro e novembro de 2008, estivemos na Escola Estadual Eusébio de Paula Marcondes e Escola Estadual Cândido Gonçalves Gomide, localizadas na Zona Sul e Oeste de São Paulo, respectivamente, tratando do PNLD e do uso do livro didático de História e de Geografia.

Em entrevistas que travamos com a coordenadora pedagógica para o Ensino Fundamental da Escola Estadual Eusébio de Paula Marcondes, Professora Cláudia Pimenta, nos pareceu que, apesar da relevância do assunto em que se insere o PNLD, em termos da atualidade de questões, como a chegada de empresas estrangeiras no mercado do livro didático, a exemplo do caso da compra da Editora Moderna pelo conglomerado de comunicação espanhol Prisa-Santillana, ao menos naquele ano, como presenciamos, os cadernos de cada uma das disciplinas, distribuídos pelo governo do Estado de São Paulo, substituindo o uso de livros didáticos, com avaliação federal, por meio do MEC, centralizaram a atenção sobre o material escrito, de distribuição gratuita realizada por meio de uma política estatal, de que dispõem os alunos das escolas públicas, em que pese, ainda, o seu significado de forte poder homogeneizante dos conteúdos aplicados nas escolas da rede estadual.

Assim, a preocupação central não se colocava, na perspectiva da coordenação pedagógica da Escola Estadual Eusébio de Paula Marcondes, em relação ao PNLD, mas com foco na política do Governo do Estado de São Paulo de distribuição de cadernos de textos e de exercícios, bem como o de orientação para os professores, para cada uma das disciplinas do Ensino Fundamental.

Corroborando a preocupação da coordenadora da Escola Estadual Eusébio de Paula Marcondes, as visitas às escolas e as entrevistas com professores dão a real medida do significado dos limites da política do Governo do Estado de São Paulo de distribuição de cadernos orientadores dos conteúdos, das atividades complementares e 
dos procedimentos pedagógicos, na concepção de professores que são obrigados ao seu uso pela Secretaria Estadual de Educação.

As críticas feitas à nova Proposta Curricular do Estado de São Paulo, efetivada, em 2008, com a distribuição dos cadernos para cada uma das disciplinas do segundo ciclo do Ensino Fundamental, são reveladoras, já que a autonomia (aspecto que precisamente é questionado duramente nas críticas realizadas ao material em questão), em sala de aula, é fundamentalmente abalada pela normatização imposta pelo material entregue pelo Governo do Estado de São Paulo. Para Rodrigo Silva, Professor de História na Escola Estadual Eusébio de Paula Marcondes, o uso dos cadernos se revela "Um exemplo claro de confusão didática",

Assim, o livro didático é pensado por outra instância que não a da escola, transformando-se em "guias de ensino", sem a devida possibilidade de crítica, particularmente no primeiro ano de seu uso, o que impõe a necessidade de reflexão sobre as possibilidades de incorporação do material como uma das mediações possíveis em relação ao conhecimento; posição muito diferente da coercitividade que deriva da utilização do material por parte do Governo do Estado de São Paulo.

A limitação em relação à necessária reflexão acerca do uso de cadernos ou livros didáticos, para muito além da política do Governo do Estado de São Paulo, encontra-se, também, no Programa Nacional do Livro Didático, tanto no que concerne ao processo de distribuição, quanto à adoção dos livros pelas escolas, numa ordem de fatores mais ampla e que diz respeito às vultosas estruturas mercadológicas e publicitárias por trás dos desacertos que com frequência encontramos relatados por professores nas escolas visitadas.

Perguntado sobre como se informava a respeito dos livros didáticos, o Professor Rodrigo Silva, da Escola Estadual Eusébio de Paula Marcondes, cujos relatos e preocupações a respeito dos aspectos da distribuição e de pedagogia, envolvendo o livro didático, são exemplares, ao nos afirmar que: "Eu pessoalmente tenho contato por referências. Eu procuro conhecer a editora, eu pesquiso em outras fontes, jornais, os catálogos na Internet"

Mas apesar de sua atitude refletida, o professor detecta sérios problemas no modo como o expediente de escolha do material se realiza no interior da escola. Sua fala

\footnotetext{
${ }^{4}$ Entrevista realizada, com o Professor Rodrigo Silva, em outubro de 2008.

${ }^{5}$ Entrevista realizada, com o Professor Rodrigo Silva, em outubro de 2008.
} 
menciona também aspectos que extrapolam o ambiente mais estrito da escola, relacionado à operacionalização da própria política pública e à política de competição que se vincula à concorrência das editoras de livros didáticos. Transcrevemos, portanto, um trecho da entrevista em que tais preocupações são levantadas:

\begin{abstract}
E tem a divulgação na escola também. Claro. Não gosto da forma como é divulgado, é uma forma apressada. Por exemplo, quando chegam para apresentar na escola, esparramam os livros na sala dos professores. Geralmente quem vem apresentar o livro não o conhece, não é leitor, não conhece a questão do mercado do livro didático. E, por outro lado, a forma como o Estado divulga isso; acho equivocado também. Não se tem uma preocupação anterior mais reflexiva, porque sempre vem o livro para a escola para escolher de um dia para outro, de uma semana para a outra. Lembro-me de uma vez, por exemplo, em que tinha um prazo de tantos dias para escolher o livro, em quinze dias, de todas as matérias, e alguém tinha que indicar, porque senão tinha um negócio online e a gente ia perder o acesso. Acabou que eu assinei a escolha da maior parte dos livros, não só de história, mas de sociologia, filosofia, literatura. ${ }^{6}$
\end{abstract}

O sentido de que, para esse professor, o processo de escolha do livro é muito apressado, o que salta às vistas à primeira passada de olhos sobre o seu relato, é bastante preocupante. O diagnóstico de que o processo de escolha se desenvolve de maneira descuidada em muito representa alguns problemas que foram recorrentemente relatados. Antes de passarmos à breve consideração de alguns desses problemas colocados nos contatos que travamos nas escolas, gostaríamos de fazer relevo de um curioso aspecto do relato acima transcrito. Quando o Professor diz que havia quinze dias para a escolha, sem o que perdiam o "negócio online" (o acesso ao portal do PNLD), estamos diante de uma questão interessante, para além da dimensão de racionalização técnica e aumento da eficiência da aplicação das políticas, a questão de como os próprios meios técnicos se convertem nos instrumentos pelos quais se processa a negociação a respeito da efetivação da política. A respeito disso, cremos que os insights que constam das teorizações corporificadas nas teorias neo-institucionalistas, que ao colocarem a ênfase da análise no poder de decisão dos corpos burocráticos, provêm uma interessante ótica a respeito da implementação de políticas públicas e sugerem questões interessantes a serem investigadas, como sugerem Peter Hall e Rosemary Taylor (2003) ${ }^{7}$.

\footnotetext{
${ }_{7}^{6}$ Entrevista realizada, com o Professor Rodrigo Silva, em outubro de 2008.

HALL, Peter A.; TAYLOR, Rosemary C. R. As três versões do neo-institucionalismo, Lua Nova, n. 58, p.193-223, 2003.
} 
O procedimento rápido foi, também, apresentado pela Professora Suzete Magliate, de Geografia, da Escola Estadual Prof. Cândido Gonçalves Gomide:

\begin{abstract}
$\mathrm{Ah}$ ! Sentam os professores de geografia da casa e vão vendo os livros; o que facilita a escolha. Olha este eu conheço! Este não conheço, mas conheço este que pega muito por este lado, ele carrega mais na história, este a geografia física fica um pouco de lado, olha este eu trabalhei o ano passado e é legal! Então, a gente vai fazendo assim a escolha. ${ }^{8}$
\end{abstract}

A Professora Suzete Magliate, ainda, revelou que há anos em que o livro não chega à escola, o que acarreta a necessidade de criar alternativas:

\begin{abstract}
No ano passado mesmo não chegou. $\mathrm{O}$ ano passado nos fizemos um grupo de professores e pegamos quinta série, professores que falam a mesma linguagem e exigem a mesma coisa; práticas que a gente está acompanhando. No meu caso, no ano passado, não tinha exemplar para todos os alunos e nem este ano. Então, o que eu faço: pego um livro volante, pego um número e vou levando para salas, pego de uma sala e vou levando para outra, vou acrescentando e eles vão fazendo um resumo para ter alguma coisa no caderno para estudar. Coisa que eles não sabem mais é o que é estudar. Sabe, eles não têm mais aquele hábito. Então eu já falei para eles: tem que prestar atenção na explicação, tirar a dúvida na hora, fazer a relação na hora, porque eu estou sempre procurando jogar o que está acontecendo, fazer uma comparação. Por exemplo, se estou falando de Rússia, de tamanho de Rússia, o que eles sabem, muito mal sabem o tamanho do Brasil. Então, eu ponho lá a área da Rússia e a área do Brasil também para fazer esta comparação. É p que eu faço quando vou falar de uma coisa, da economia de algum país. Eu faço assim para sair do que eles conhecem; para eles entenderem melhor o que está sendo discutido. Então, o livro a gente vai usando, mas está difícil para eles. ${ }^{9}$
\end{abstract}

A questão de criar alternativas para utilização do livro didático é uma situação recorrente na fala dos entrevistados, pois um único livro didático adotado pela escola, muitas vezes, não é capaz de solucionar as necessidades de uma aula específica ou de várias aulas, isto é exposto pelo professor de História Jorge Aparecido da Silva, da Escola Estadual Cândido Gonçalves Gomide que afirma não ser centrado em um único livro e também revela a necessidade de sempre estar pesquisando outros materiais para planejar uma aula.

Eu comecei com Raimundo Campos, mas nunca fui muito centrado no livro. De repente, eu adotava um livro didático, mas eu usava o conteúdo daquele, um eixo, mas de repente aquele outro livro estava melhor. Então, eu retirava

\footnotetext{
${ }^{8}$ Entrevista realizada, com a Professora Suzete Magliate, em novembro de 2008.

${ }^{9}$ Entrevista realizada, com a Professora Suzete Magliate, em novembro de 2008.
} 
o conteúdo do outro livro. Então fui mesclando vários livros. Um livro extra para o pessoal fazer exercícios e tudo mais, mas fui mesclando. E isso foi para te falar a verdade durante muito tempo, naquela época em que aluno comprava ainda livro didático. Aí nos chegamos há um tempo em que a escola oferece, a secretaria manda a listagem e os exemplares e o professor escolhe. Olha, muitas vezes aquele que nos escolhemos não é aquele que vêm. Então, você tem a opção de ter o livro e mais duas opções, geralmente vem a segunda ou a terceira opção. E no meu caso então eu continuo fazendo isso, pois, eu tenho mais ou menos a idéia do conteúdo, estou sempre lendo e sempre revendo, então eu adoto aquele livro que vem para escola. Adoto, eu tiro exercícios, eu levo para sala de aula, trago de volta, pois, muitas vezes o número de livro não é suficiente para toda clientela, muitas vezes você leva e traz, leva e traz. Mudo sempre, vou à biblioteca e pego outro livro. Durante uns cinco, seis anos eu trabalhei em uma escola em Osasco, e lá eles tinham uma apostila, então, de vez em quando eu lembro, eu tenho o exemplar desta apostila, então eu tiro daquela apostila, muitos fatos recentes eu coloco o que está no livro, mas coloco que já temos pesquisas recentes abordando aquele assunto, e assim vou indo. Eu não fico centrado num livro só, o livro que mandam para gente, que a "FLEI" manda para gente, eu pego alguns conteúdos e vou levando, mais ou menos isso que eu faço. ${ }^{10}$

Verificamos, nas falas do professor Jorge e da professora Suzete, a importância do professor ter o direito à escolha do livro didático que será adotado pela escola, pois seu planejamento de aula está ancorado no material que estará disponível ao aluno, por mais que não exclusivamente.

O Professor Jorge Aparecido da Silva, de História, da Escola Estadual Cândido Gonçalves Gomide, apontou a existência de um problema muito particular da sua área de conhecimento, relativa à distribuição dos conteúdos, o que corrobora para as dificuldades no uso do livro didático que, ao ser escolhido um único por escola, não permite a diversidade de posturas de estruturação dos conteúdos ao longo das séries.

Hoje, até pouco tempo atrás nos estávamos escolhendo o Divalte para o ensino médio, agora o fundamental em história aconteceu um problema muito sério... aconteceu um caso sério, é o seguinte, quando eu cheguei aqui nesta escola, isso aconteceu em 1993, então, nos tínhamos mais ou menos o seguinte: quinta série nos tínhamos história do Brasil, colônia, colônia e um pedacinho do reinado; na sexta série você pegava então o resto do império e república do Brasil; na sétima série você pegava história antiga e medieval; na oitava série, moderna e contemporânea. Sempre nos tivemos assim. Aí por volta de noventa e seis, noventa e sete surgiu à outra série que colocava o seguinte: era o mesmo conteúdo, mas dividido de forma diferente. Era o mesmo conteúdo, mas, por exemplo, na quinta série você pegava a história geral, que no caso seria antiga e medieval; na sexta série, você pegava a medieval e já encaixava a história do Brasil; na sétima série, moderna já encaixando história do Brasil; e na oitava série, contemporânea e história do Brasil. Na verdade, o conteúdo é o mesmo; a forma de didática que é diferente, mas tem um negócio, ou você trabalho com um, ou você trabalha

\footnotetext{
${ }^{10}$ Entrevista realizada, com o Professor Jorge Aparecido da Silva, em novembro de 2008.
} 
com o outro; encaixar os dois não dá, porque se torna repetitivo. E alguns professores aqui fizeram isso, mostram aquele modo tradicional, e os professores que vieram e adotaram este novo sistema. Então nos tínhamos classes aqui, por exemplo, que tinham um conteúdo que a outra não tinha. Então, de repente, o aluno da quinta série passava para sexta e o outro professor tinha dado de forma diferente. Nós tentamos várias vezes centralizar em reuniões, planejamento e tentando unificar, mas chegava na hora $\mathrm{H}$ cada professor dava o que queria. Então nos ficamos mais ou menos perdidos. Agora de uns três anos para cá que resolvemos novamente, então vamos reunificar, estamos tentando. Então no ensino fundamental dois, nós tínhamos este problema. Agora, nós estamos fazendo da seguinte forma: quando nos chegarmos à quinta série que vai ser tudo sexto ano devido a esta modificação que vai acontecer, nos vamos para história antiga ter história medieval; quando chega ao sétimo ano, moderna e contemporânea e assim vai. Mas, para eles a gente unifica, porque infelizmente os professores mais antigos aposentaram e os mais novos que vieram, vieram com estes vícios de outras escolas, é por isso que nos ficamos mais ou menos perdidos em história no ensino fundamental. No ensino médio, já foi mais fácil. No ensino médio, nos começamos com história do Brasil e história antiga no primeiro colegial; no segundo colegial, história do Brasil; e no terceiro colegial, história do Brasil, história geral e atualidades. ${ }^{11}$

Assim, os desacertos a que frequentemente os professores aludem dizem respeito a uma gama muito diversificada de problemas. Vão desde aspectos muito específicos concernentes à materialidade do livro a questões mais amplas, como as didáticas. Ouvimos algumas vezes, por exemplo, professores reclamarem da dimensão do livro didático. Foi-nos mostrado pelo Professor Rodrigo Silva, a título de exemplo, um livro adotado anos antes pela escola, da disciplina de história, utilizado no Ensino Médio que trazia condensado o conteúdo dos três anos, com extensão de mais de quinhentas páginas. Esse aspecto aparentemente superficial foi assunto de caloroso debate em que alguns professores pareciam duvidar da índole dos alunos que alegavam o motivo do sobrepeso para não carregarem seus livros para a escola, ao passo que alguns professores pareciam endossar a crítica.

Crítica semelhante, em relação ao peso dos livros didáticos, apareceu na fala da Professora Sandra Lúcia Laki, atual diretora da Escola Estadual Cândido Gonçalves Gomide, que, mesmo ao salientar a importância do livro no processo de ensinoaprendizagem, afirma que:

O uso do livro didático eu acho muito importante para o aluno, pois ajuda bastante, o que posso afirmar porque sou professora. Estou atuando como diretora, mas sou professora de português. E o livro didático auxilia muito nas aulas de língua portuguesa. Então, eu vejo a importância deste livro na

\footnotetext{
${ }^{11}$ Entrevista realizada, com o Professor Jorge Aparecido da Silva, em novembro de 2008.
} 


\begin{abstract}
atuação do professor em sala de aula. Mas, atualmente, como esta sendo feito não está tendo resultado como deveria ter, porque hoje o aluno tem muitos livros para carregar e acabam não os trazendo para escola. E quando você acha que o aluno tem os livros, ele acaba não trazendo para escola para utilizar na aula, que seria o objetivo. Os alunos não trazem porque os livros vêm para o ensino médio e, como eles já são para os três anos, são muito grandes. ${ }^{12}$
\end{abstract}

A Diretora Sandra Lúcia Laki salientou, ainda, problemas concernentes à logística de distribuição, em que se pese a dificuldade em fazer chegar às escolas o número necessário de exemplares para cada turma, já que não é enviada a quantidade real de exemplares em relação ao número de matriculados por turma, podendo haver complementação até mesmo com livro não adotado na escola, o famoso livro "reserva", o qual não teria utilidade alguma por não se constituir em um exemplar a mais, e sim em um livro diferente a mais. Outro problema, ainda, apontado pela Diretora Sandra Lúcia Laki, é o da quantidade de livros que chegam para distribuição de uma única vez, dificultando o funcionamento da própria escola no que concerne ao uso dos restritos espaços disponíveis, requerendo alterações nos procedimentos de distribuição dos livros.

Para mim tem que ser totalmente diferente. Até fiz um trabalho de PLND quando participei de um curso. A logística também é toda errada porque as escolas não têm espaço suficiente para armazenamento. Está é a segunda escola em que trabalho e aqui nos temos mais espaço para receber o livro. Vamos por onde? Nós começamos a por em qualquer lugar. Não há lugar para deposita-los antes da distribuição para os alunos. Então, é no corredor atrapalhando passagem. E aqui também [sala da direção]. Vai para onde? Se for para sala da coordenação, não haverá espaço para fazer mais nada lá. ${ }^{13}$

Uma parte razoável das críticas colocadas ao livro faz eco a preocupações didáticas que surgem na fala dos professores, dos coordenadores e dos diretores das escolas públicas do Governo do Estado de São Paulo.

Assim como as entrevistas revelaram, especificamente a respeito do uso do livro didático, na disciplina de Geografia, questões teóricas acerca do enfoque (o debate acerca da pertinência de separar, didaticamente, uma Geografia sobre Brasil e outra sobre o "resto" do mundo), questões teóricas próprias ao campo da História informam

\footnotetext{
${ }^{12}$ Entrevista realizada, com a Professora Sandra Lúcia Laki, em novembro de 2008.

${ }^{13}$ Entrevista realizada, com a Professora Sandra Lúcia Laki, em novembro de 2008.
} 
também a problematização do uso desses materiais nessa disciplina. Segundo o Professor Rodrigo Silva:

Outra coisa também que eu vejo dentro já do conteúdo do livro é, geralmente, os índices. Há uma linearidade, que é a construção do progresso, a visão do progresso, no sentido cronológico, como se a História ocorresse linearmente. Eu acho um equívoco didático. Mas não é só uma postura didática, é uma postura ideológica, claro. Outra coisa, bem pensando é o contexto do livro. Não aprovo muito, por exemplo, muitas imagens terem legendas. Se está no corpo do texto, podia tirar a legenda, seria mais interessante. Há muita legenda. $^{14}$

Essa observação que o Professor faz pode ser contraposta à concepção que pareceu prevalecer nos contatos que tivemos, tanto com professores de Geografia, como com professores de História, segundo a qual o livro deve ser encarado como um material a mais, não se definindo pela sua utilização o ofício do Professor. Cremos ser muito válido ressaltar essa distinção, porque, como colocamos acima, há uma questão importante, no momento atual, nas escolas, que é o da perda da autonomia do professor. Assumindo a relevância dessa questão, percebe-se que a crítica direcionada ao livro didático constitui sua relevância na medida em que se direciona ao uso que dele é feito. Em contraposição ao material distribuído pela Secretaria de Educação do Governo do Estado de São Paulo, com o fito de padronizar a proposta didática, aqueles professores que têm adotado uma postura crítica tendem a elogiar o livro em alguma medida.

O Professor Rodrigo Silva, de forma bastante contundente, assume uma postura de extrema criticidade em relação ao uso do livro didático, chegando a questionar: "o livro didático pode ficar no lugar do professor?" ${ }^{15}$. Para o Professor Rodrigo Silva, o livro deve ser uma mediação na elaboração das aulas; nunca assumindo o significado de "guia de ensino":

É uma boa questão, porque ficou uma coisa como um guia de ensino. Ele, por ser um elemento de pesquisa - eu não sou contra o livro didático - eu posso usar o livro didático para pesquisar vários elementos, como, puxa, como trabalhou aquele tema, aquele historiador, como que outro trata aquilo. Eu acho detestável qualquer livro didático que tenha resposta no livro do professor, é uma muleta e tanto. Não concordo com isso. Porque isso desestimula a formação do professor. Corrobora para a má formação do

\footnotetext{
${ }^{14}$ Entrevista realizada, com o Professor Rodrigo Silva, em outubro de 2008.

${ }^{15}$ Entrevista realizada, com o Professor Rodrigo Silva, em outubro de 2008.
} 
professor também. Voltando ao livro didático, você pode usar livros para construir temas. ${ }^{16}$

Outra preocupação que percorre o debate acerca do livro didático é a concernente à dimensão mercadológica envolvida na concorrência pela adoção de livros pelas escolas. Assim, é bastante razoável sugerir que a crítica da irreflexão que marca a relação com o livro didático, da escolha ao uso, segundo alguns professores, encontra expressão na estratégia de persuasão perceptível, mais uma vez, no próprio corpo do livro, no qual mal se dissimularia uma intenção publicitária nos livros quando, desde a capa, se percebe um apelo mercadológico ${ }^{17}$.

Ficam expostos, pelas considerações, alguns problemas do livro didático. Enfatizamos, no entanto, que as críticas não apontam para uma desconsideração completa do significado desse instrumento didático no processo ensino-aprendizagem. As críticas nos revelam problemas que se localizam desde a implementação do Programa Nacional de Livro Didático até a sua operacionalização final, chegando ainda ao debate da sua validade didática, o que fica mais evidente na política de distribuição de cadernos pelo Governo do Estado de São Paulo, quando a autonomia do professor é muito mais cerceada.

Por fim, é importante ressaltar o nexo que localiza mais amplamente o problema da escolha do livro didático nas escolas públicas paulistas, mas, também, do Brasil: a escala das estruturas mercadológicas na conformação dessas políticas, ordem de fenômeno sobre o qual seria ao menos pertinente inquirir se não estaria traduzindo em realidade e potencializando a ausência de reflexão mais aprofundada do significado político, econômico e social do Programa Nacional de Livro Didático que localizamos em nossas observações.

No entanto, a importância do livro didático no contexto escolar, particularmente no processo ensino-aprendizagem, não pode ser desprezada, conforme salienta Neiva Otero Schäffer:

"Deve-se considerar que, apesar das múltiplas críticas, o empenho do parque editorial e as perspectivas de matrículas crescentes nas séries finais do ensino fundamental e no ensino médio, pressionadas pelo avanço da escolarização, abrem um espaço ampliado e um futuro

\footnotetext{
${ }^{16}$ Entrevista realizada, com o Professor Rodrigo Silva, em outubro de 2008.

${ }^{17}$ Entrevista realizada, com o Professor Rodrigo Silva, em outubro de 2008.
} 
garantido para a permanência do livro didático de geografia. O que se precisa enfatizar é a necessidade de maior exigência com a qualidade, com a procura por uma diversidade séria de textos, no qual inicia a ter um crescente papel o livro paradidático, e com textos de caráter regional que insiram temas transversais, necessidades estas que emanam dos documentos legais, como a Lei de Diretrizes da Educação Nacional (LDB) e os PCNs" (SCHÄFFER, 1998:140)

Assim, cabe-nos, para concluir, indicar que os liames em que se envolve o livro didático não são de fácil intelecção, mas superar o preceito mercadológico, como fundamento da passagem da escolha ao uso, não deve ser uma regra, mesmo em um mundo marcado pelo crescente número de matrículas, o que se tem verificado nos cuidados tomados pelas inúmeras comissões, formadas pelo MEC, na avaliação dos livros junto ao PNLD, reformulando critérios e realizando as avaliações dos livros e das coleções, sempre, por pares de professores para cada exemplar, o que se configura em fundamento para uma leitura, ainda, mais criteriosa ao capturar críticas de sujeitos com experiências e posturas acadêmico-pedagógicas diversas, além do cuidado em se realizar uma avaliação "cega", na qual os avaliadores desconhecem a autoria e a origem editorial do livro ou da coleção em análise.

Com a crescente exigência presente nos processos de avaliação, nos últimos anos, tem havido uma melhoria sensível na qualidade dos livros didáticos, o que nos possibilita afirmar que a discussão da gestão democrática da escola e do Estado e a melhoria do padrão dos livros didáticos vislumbram a concretização de um sonho, no futuro, em que não haja diferença entre a escolha e o uso do livro didático de Geografia e de História nas escolas públicas brasileiras, com reflexões bastante conscientes dos professores acerca dos limites e das possibilidades do material selecionado.

\section{REFERÊNCIAS}

BLOIS, Marlene Montezi. Livros para que? Revista Tecnologia Educacional, Rio de Janeiro: Associação Brasileira de Tecnologia Educacinonal, v.VIII, maio/jun.1979.

CARVALHO, Lídia Ezecson de. A distribuição e circulação de livros nas escolas paulistas. São Paulo: PUC-SP, 1991. (Dissertação de Mestrado) 
CASSIANO, C. Reconfiguração do mercado editorial brasileiro de livros didáticos no início do século XXI: história das principais editoras e suas práticas. Em Questão, Porto Alegre, v.11, n.2, p.281-312, jul./dez.2005.

FREITAG, Bárbara; COSTA, Wanderly F. da; MOTTA, Valéria R. O livro didático em questão. São Paulo: Cortez, 1989.

HALL, Peter A.; TAYLOR, Rosemary C. R. As três versões do neo-institucionalismo, Lua Nova, n. 58, p.193-223, 2003.

HOFLING, Eloísa de Matos. Notas para discussão quanto à implementação de programa de governo: em foco o Programa Nacional do Livro Didático. Revista Educação e Sociedade, n.70, p.159-169, abr.2000.

MUNAKATA, Kazumi. Produzindo livros didáticos e paradidáticos. São Paulo: PUCSP, 1997. (Dissertação de Mestrado)

OLIVEIRA, João Batista Araújo. Os livros descartáveis: Exigência pedagógica ou apenas um bom negócio? Cadernos de Pesquisa - Revista de Estudos e Pesquisas em Educação, São Paulo, n.44, fev.1983.

PETRONE, Pasquale. O ensino de Geografia nos últimos 50 anos. Revista Orientação, São Paulo: Instituto de Geografia/USP, n.10, p.3-17, 1993.

SCHAFFER, Neiva Otero. O livro didático e o desempenho pedagógico: anotações de apoio à escolha do livro texto. In: CASTROGIOVANNI, Antonio Carlos et alii (orgs.). Geografia em sala de aula; Práticas e reflexões. Porto Alegre: AGB-Seção Porto Alegre, 1998. p.129-142.

SOARES, Maria Lúcia de Amorim. Diferentes propostas dos livros de Geografia e Estudos Sociais. Revista Orientação, São Paulo: Instituto de Geografia/USP, n.10, p.6171, 1993.

VESENTINI, José William. A questão do livro didático no ensino da Geografia. In: 179. (Org.). Geografia e ensino; textos críticos. Campinas: Papirus, 1989. p.161-

VLACH, Vânia Rubia Farias. Carlos Miguel Delgado de Carvalho e a "orientação moderna" em geografia. In: VESENTINI, José William (Org.). Geografia e ensino; textos críticos. Campinas: Papirus, 1989. p.149-160. 